\title{
Huellas romanas en la provincia de Córdoba. Calzadas y puentes
}

\author{
F. Javier Rubiato Lacambra \\ Doctor en Historia del Arte \\ Universidad de Córdoba
}

\section{Resumen}

De todo el patrimonio romano, las vías de comunicación y los puentes han sido en gran medida el legado más característico. El presente artículo, que se centra en la actual provincia de Córdoba, revisa la estructuración de las calzadas en dicha zona, analizando el modo de actuación de este pueblo ante la ocupación del territorio y los desplazamientos. Además se repasan los rasgos generales de los puentes y se estudian las obras existentes. Por otro lado, se trata de hacer una llamada de atención, con el fin de tomar conciencia de la necesidad de preservar y conservar unas obras que trascienden su objetivo funcional, para ser consideradas como auténticos monumentos, en definitiva piezas clave de la Historia del Arte.

\section{Palabras clave}

Hispania Romana / Calzada / Puente / Preservación / Conservación.

El puente, como el resto de las obras públicas -acueductos, vías, túneles, etc.-, apenas es reconocidas como patrimonio, salvo en círculos pequeños, de ingenieros, historiadores del arte y arqueólogos. Los admiran los primeros por sus aspectos técnicos, y lo otros, por las soluciones estéticas y evolución del pensamiento que la obra en sí conlleva. El hecho de servir a una misión funcional parece restar importancia a estas obras'. Esta mentalidad se generaliza desde el pueblo hasta las más altas instituciones que, en aras de lo práctico y el progreso, han sacrificado en gran número de ocasiones obras de indudable valor histórico.

De todas las obras públicas, el puente "por su vuelo constante" es el resultado de los avances técnicos y científicos de la civilización de la que es fruto, pero también de su pensamiento estético y de su situación económica, política o social, es decir, de su historia. Cada pueblo, cada civilización, ha impreso en el puente su modo de ver la vida y sus más altos conocimientos porque, no en vano, uno de los retos más grandes a lo largo de la historia ha sido salvar obstáculos tan inmensos como los ríos, auténtica pesadilla durante largos siglos, en los que la técnica estaba muy por debajo de las necesidades que se pretendían resolver. Simboliza el triunfo del ingenio humano frente al reto de la naturaleza. Es, en definitiva, como escribió Arenas de Pablo, "pieza clave del desarrollo de la civilización" 2.

Previo al estudio del puente, hay que tener en cuenta que éste forma parte imprescindible del camino, punto clave y sobresaliente del mismo. No se entiende el puente aislado y no tiene sentido. Forma parte de una obra mayor: la red de caminos, de vías, de carreteras. Es necesario situar cada puente en un marco geográfico, estudiando previamente el medio físico en que se encuentra y la vía de comunicación de la que forma parte. De ahí que haya sido necesario realizar un análisis previo de las vías de comunicación en tiempos de Roma en la provincia de Córdoba, ámbito espacial al que se refiere este articulo, estudiando previamente el marco geográfico o medio físico que lo soporta.

Por otro lado, el puente, como importante legado patrimonial tanto desde el punto de vista técnico como artístico, que ha evolucionado a lo largo de la historia, merece un estudio de las características formales que ha ido adquiriendo a lo largo de la misma, considerando sus rasgos y resaltando los ejemplos más destacados que encontramos en la provincia. 


\author{
Los puentes evidencian más que ninguna otra obra los avances \\ técnicos de la sociedad que los construyó, pues son el reflejo de \\ la misma (...) Son por tanto expresión artística de sus \\ constructores y más que cualquier otro monumento reflejan los \\ intereses de la sociedad que los necesitó.
}

Córdoba tiene un rico patrimonio en puentes romanos, en la mayoría de los casos muy desconocido. Esto se debe además de a su dilatada historia a su variada topografía, la abundancia de ríos y arroyos que es necesario cruzar, y a la presencia del Guadalquivir, el Betis de los romanos, que dio nombre a la región, así como al importante valor estratégico en el corazón de Andalucía. Es, pues, la provincia una auténtica encrucijada de caminos.

\section{Marco Geográfico}

La provincia de Córdoba ocupa por un lado el centro de Andalucía y por otro se introduce como una cuña sobre la Meseta. Esta situación excepcional dentro del marco de Andalucía y de España le hace participar de dos unidades físicas diferentes y la conforman, desde el punto de vista morfológico y tectónico, como dos unidades de relieve distintas: la Campiña y la Sierra. El tercer elemento característico de la provincia y que completa el paisaje es el río Guadalquivir, que discurre de este a oeste, casi por el centro de su superficie, constituyéndose en el eje geográfico e histórico, así como en vía de comunicación y nexo de unión por un lado y frontera entre las dos unidades antes citadas, que conforman la realidad paisajística.

Analizando más detenidamente cada una de estas unidades, se puede observar cómo la Sierra está muy condicionadas por su orografía, que se hace sentir en los ríos cortos y relativamente rápidos, como el Guadiato, el Guadalmellato y el Bembézar. La segunda unidad, la Campiña, constituida por la depresión del Guadalquivir, antiguo brazo de mar que se ha ido colmatando desde el Cuaternario, se trata de un paisaje alomado, de suaves pendientes, en el que domina la llanura, pero no la monotonía, con lo que resulta agradable a la vista y en ocasiones sorprendente. En esta zona tanto los caminos como los ríos no parecen ser forzados por las condiciones orográficas. Los ríos, como el Genil, que es el más largo de los afluentes del Guadalquivir, o el Guadajoz, discurren en dirección sureste-noroeste.

Ambas zonas son bien distintas, no sólo morfológica y geológicamente, sino también desde el punto de vista humano, aspecto éste último en el que hay una gran diferencia: la Campiña está muy poblada, abundando en ella los grandes núcleos urbanos, como Montilla, Puente Genil, Lucena, etc., con gran actividad, mientras la Sierra y el resto de la zona norte se encuentra más despoblada y los núcleos de población (Espiel, Fuenteovejuna, Belalcázar, etc.) por lo general son más pequeños. En cuanto a las vías de comunicación, ocurre lo mismo: la red es mucho más densa en el sur que en el norte.

\section{Las Vías de Comunicación}

En una visión general, los caminos y vías son más densos en la Campiña que en la Sierra, pero la provincia de Córdoba en este aspecto viene determinada por la presencia del río Guadalquivir, que la atraviesa en dirección este-oeste, como antes se dijo. El río fue desde antiguo la primera vía de comunicación de la provincia, gracias a su navegabilidad, hoy perdida, pero que antaño llegaba a la localidad de Villa del Río, límite con la provincia de Jaén.

Quizá por la configuración del río y por su navegabilidad, los caminos y las comunicaciones a lo largo de la historia han tendido a ir al lado del mismo. Hay que tener en cuenta el gran desarrollo en superficie que representa la cuenca del Guadalquivir, en relación con el resto de Andalucía, con más del 65 por ciento del territorio bético, y la facilidad que supone el atravesar el valle frente a las sierras.

Por otra parte resulta interesante observar la situación en este marco geográfico de la capital y principal ciudad, Córdoba. Además de ser el centro administrativo, político y comercial, su situación a orillas del gran río y prácticamente en el centro del territo- 
rio provincial, la convierte en el polo de atracción tanto de la Sierra como de la Campiña y nudo fundamental de las comunicaciones con todas las poblaciones de la provincia y más allá de este ámbito: Sevilla, Málaga, Madrid, Badajoz, etc. Esta envidiable situación estratégica ha sido la causa fundamental de su importancia a lo largo de la historia.

Córdoba ciudad es, pues, un nudo de comunicaciones desde el mismo momento de su fundación ${ }^{3}$, durante la conquista por Roma, que aprovechó la existencia de un poblado indígena, no sin antes percatarse de la buena situación. Como toda ciudad romana fundada por militares, contó con los ejes de ordenación característicos romanos: "cardus" y "decumanus". Ambas vías principales hoy es difícil distinguirlas por las sucesivas superposiciones que ha ido sufriendo la primitiva traza ortogonal del antiguo campamento romano, cosa natural teniendo en cuenta el tiempo transcurrido y la condición de que la ciudad, como organismo vivo, va evolucionando, cediendo a las necesidades del tráfico y de la comunicación en todos los tiempos.

\section{Calzadas Romanas}

Las excavaciones y los restos arqueológicos encontrados, testimonios como los "miliarios" encontrados en 1677 en esta ciudad y distintos documentos como el "itinerario Antonino" 4 ayudan a hacerse una idea de los caminos o vías romanas de la Bética. Las primeras vías romanas son de época republicana, aunque la mayor labor constructiva se llevó la cabo en la época imperial. La Vía Hercúlea ${ }^{5}$, o vía exterior, comunicaba Hispalis con Roma ya antes del 124 antes de Cristo, siguiendo un camino desde Emporiae (Ampurias), Cartago Nova (Cartagena) hasta Gades (Cádiz). En tiempos de Augusto se va a dar un nuevo impulso constructor, afectando en Hispania al trazado de la antigua vía, en la que se restauran los desperfectos ocasionados por el tráfico y el tiempo. Pasa entonces a llamarse Vía Augusta ${ }^{6}$, que fue la principal vía de comunicación, tanto dentro de la Bética como de ésta con el resto del Imperio y Roma. La ruta seguida por esta vía dentro de la provincia vendría desde Castulonem (Cástulo), provincia de Jaén, transcurriría por el margen izquierdo del río, pasaría por Ad Noulas (Villanueva de la Reina), también por lliturgi (Andújar) , Eporam (Montoro), Ad Decumo (Villafranca de Córdoba), Corduba (Córdoba), Ad Aras (Cortijo de las Siete Torres), Astigi (Écija), Obucula (La Monclova), ya en la provincia de Sevilla, Carmo (Carmona) e Hispalis (Sevi$\|$ la), y terminando en Gades (Cádiz).

Es interesante señalar que la vía transcurría paralela al río hasta Córdoba y que a partir de allí tomaba la dirección suroeste, idéntica a la actual carretera Nacional IV, alejándose del río. Por otra parte, la vía cruzaba el río al menos en dos ocasiones, una antes, en la provincia de Jaén, en la localidad de lliturgi (Andújar), donde existe un puente romano, y otra en la salida de Córdoba hacia Hispalis (Sevilla), en las puertas de la ciudad, por medio del conocido puente de Córdoba ${ }^{7}$. Es muy probable que también lo cruzara en Alcolea por un puente desaparecido, pero igualmente de origen romano, que fue sustituido en tiempos de Carlos III por una bella obra de fábrica.

\section{Caminos secundarios romanos}

Pero la Vía Augusta, siguiendo el itinerario de Antonino ${ }^{8}$, se duplicaba por el margen izquierdo del Guadalquivir. Así, desde Castulo llegaba a lliturgi, de allí a Virgaone (La Aragonesa, hoy término de Marmolejo), Calpurnia (El Carpio), Corduba (Córdoba), y a partir de aquí tomaba dirección sur hacia Ulia (Montemayor), Ipagro (Aguilar de la Frontera), Angelus (Benameji), Caria (Antequera), y Malaca (Málaga).

Esta alternativa a partir de Corduba sería el antecedente de la actual carretera Nacional-33I, Córdoba a Málaga por Antequera, siendo en realidad una vía secundaria de la vía Augusta. El trayecto de Montemayor a Benamejí es el más interesante, encontrándose ruinas romanas en las proximidades del camino: Los Baños de Horcajo, Los Moriles y Silpia, en Las Navas del Selpillar.

Otra vía secundaria, "Iter Corduba ad Emeritam", según el itinerario Antonino, se situaría en la zona norte. Iría de Corduba (Córdoba) a Mellaria (Fuente Ovejuna), Metellium (Medellín), ya en Extremadura, y Emerita Augusta (Mérida). Una tercera vía uniría Córdoba con Toledo por la comarca de los Pedroches. Iría a Cerro Muriano y de allí a Belalcázar, donde existe un puente romano. A partir de allí se adentraría la vía en la Meseta.

Estas vías secundarias de la vía Augusta confirman la teoría de la existencia de caminos rápidos que acortaban la distancia y el tiempo de desplazamiento. Permitían el traslado de los ejércitos y las mercancías en velocidades hasta entonces no concebibles, contadas en días, por supuesto, que hoy nos pueden parecer lentas, pero que permitieron a los romanos dominar toda la cuenca del Mediterráneo y los territorios adyacentes, lo que fue transcendental para todos los pueblos indígenas de la misma.

\section{Los Caminos después de Roma}

Posteriormente, en tiempos de los visigodos, la red de comunicaciones no debió variar respecto a la establecida por los romanos 9 . Son varias las razones que nos llevan a pensar que no aumentó la red de vías. Por un lado, las necesidades del tráfico disminuyeron y por otro las que había estaban cubiertas por la red ya existente. Además, la ocupación romana había dejado en perfectas condiciones la mayoría de las infraestructuras, pues habían sido sólidamente construidas y bien mantenidas. Por otro 
lado, el menor desarrollo técnico del pueblo visigodo dificultó la construcción de grandes obras, especialmente de los puentes 10

Lo que sí es cierto es que, a pesar de las dificultades políticas, los visigodos de la Península se ocuparon del mantenimiento y conservación de las vías romanas y de los puentes, lo que puede atestiguarse en puentes de origen romano como el puente antiguo de Córdobal'. Las vías naturales debieron ser más utilizadas. En ese sentido, en la provincia de Córdoba los caminos hacia Toledo, por razones de capitalidad, serían más transitados que en la época romana, pero en general la red viaria no cambió excesivamente.

\section{Puentes Romanos de Córdoba}

Los puentes evidencian más que ninguna otra obra los avances técnicos de la sociedad que los construyó, pues son el reflejo de la misma y obedecen a los gustos estéticos en lo posible, teniendo en cuenta la técnica del momento. Son por tanto expresión artística de sus constructores y más que cualquier otro monumento reflejan los intereses de la sociedad que los necesitó. No queda nada en la provincia de puentes anteriores a los romanos, aunque sin duda los hubo, como ocurrió en el resto del territorio ocupado, según han demostrado distintos autores. ${ }^{12}$ De este modo los puentes más antiguos que han llegado hasta nosotros corresponden a esta etapa histórica. Roma, con su política de expansión territorial, creó una vasta red de vías que comunicaban el imperio con la capital, facilitando con ello la comunicación como nunca antes se había visto.

De muchos puentes romanos sólo quedan pequeños restos o alguna pequeña referencia bibliográfica. En la provincia de Córdoba tenemos la suerte, por ser un punto estratégico en el dominio de la Bética, de encontrar restos de varios puentes romanos, algunos de ellos en muy buen estado. El problema de los que tenemos es que en muchos casos hoy es difícil discernir lo que es romano de lo que no lo es, a causa de las múltiples modificaciones sufridas a lo largo de la historia.

Los puentes romanos se caracterizan, independientemente de su tamaño, relacionado de forma directa con el cauce que cruzan, por su solidez, que lleva aparejada una sensación de monumentalidad, por pequeña que sea la obra. Siempre son de fábrica de piedra, cortada en grandes sillares, utilizando a veces el hormigón en el interior de las pilas o en las fundaciones, que curiosamente siempre coinciden con el terreno más consistente de la zona, pues buscaban las zonas de roca para la cimentación, eligiendo para ello el lugar más adecuado.

La utilización de la piedra y el hormigón hidráulico va a dar a la obra un aspecto de gran solidez. Siempre utilizan la bóveda de cañón, generada por el arco de medio punto, apoyada sobre robustas pilas,

en muchos casos con una proporción respecto al vano de un tercio o incluso de un medio, lo que es problemático, pues crea una gran resistencia a la corriente a la que se interponel3. De ahí la presencia casi generalizada de aliviaderos o pequeñas bovedillas sobre las pilas (puente de Villa del Río) o de óculos en los estribos y tímpano, como en el puente de Andújar provincia de Jaén.
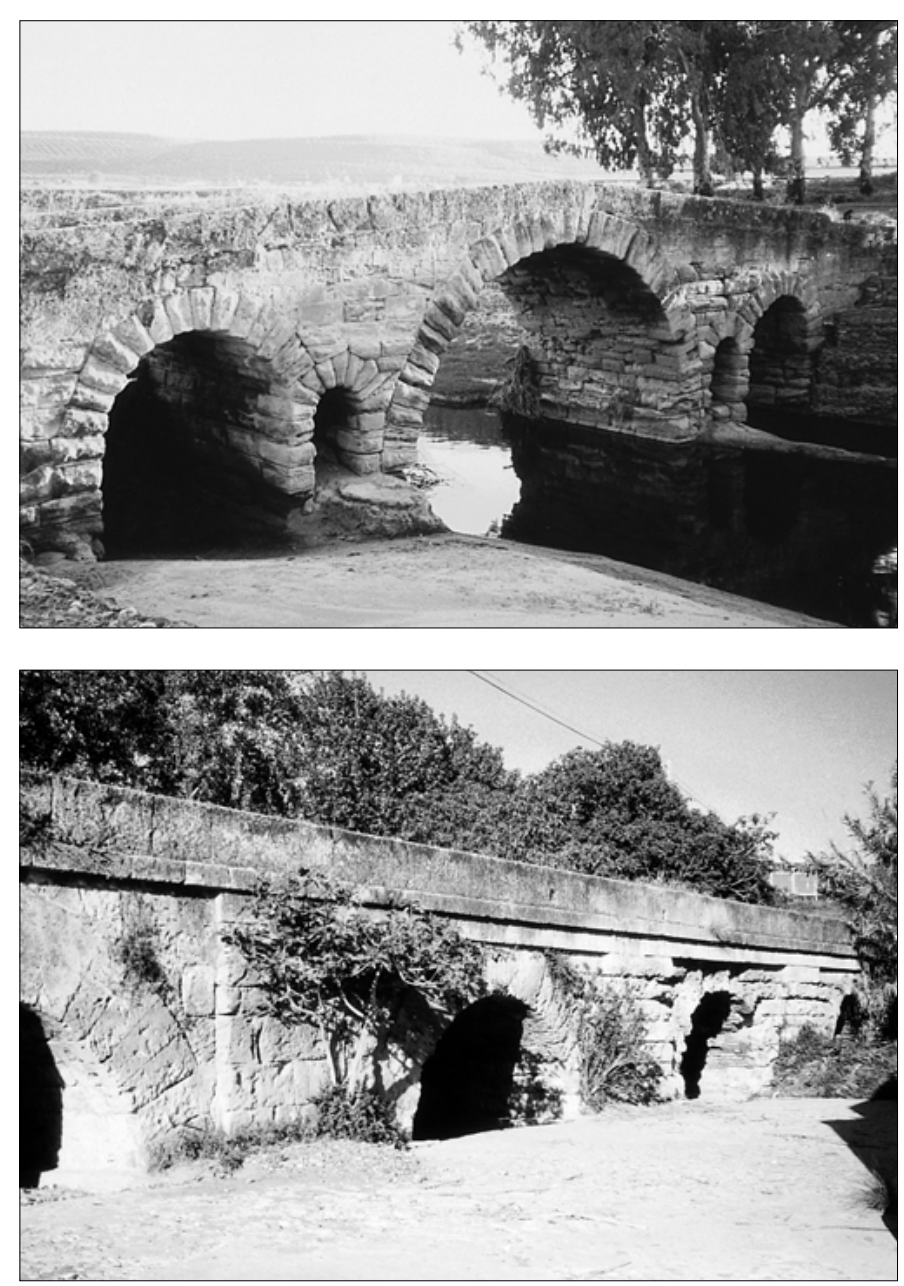

El aparejo usado suele ser muy cuidado, siendo normalmente sillares y en puentes pequeños el sillarejo. Las pilas se completan con grandes tajamares que se adaptan a la corriente, hidrodinámicos, triangulares aguas arriba y semicirculares aguas abajo. Sobre ellos se sitúan los sombreretes o remates. Las bóvedas se destacan del tímpano por la posición de sus dovelas y de la rasante del tablero que suele seguir la línea de impostas.

\section{Las obras}

Los puentes romanos de la provincia que quedan en pie son: el de Villa del Río, sobre el río Salado, el de Rabanales, sobre el arroyo del mismo nombre, el "Puente Mocho", sobre el Guadalmellato, el de Los Pedroches, sobre el arroyo del mismo nombre, en las afueras de Córdoba. El Puente de Córdoba, el
Fig. I: Puente de Villa del Río, sobre el río Salado.

Fig. 2: Puente de Rabanales, sobre el arroyo del mismo nombre. 


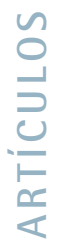

Fig. 3: El "Puente Mocho", sobre el Guadalmellato. Fig. 4: El "Puente Viejo", sobre el Guadajoz.
Puente Viejo, sobre el Guadajoz, el que está sobre el Guadatín, próximo a Villafranca de Córdoba y "La Pontilla", sobre el arroyo Malperdido. Éste último obra de carácter menorl4.

De los puentes romanos de la provincia, por su antigüedad, diseño y buen estado, destaca el de Villa del Río sobre el arroyo Salado (Fig. I). Muy próximo al Guadalquivir, se construyó para dar paso a la vía Hercúlea, sobre el pequeño arroyo que desemboca a la izquierda del gran río. Dotado de indudable valor estético e histórico, fue declarado monumento histórico artístico el 3 de julio de 1931, junto con otros puentes de la provincia, el de la capital, y el de la Tejera, de tiempos del Califato.

Puente de la época republicana ${ }^{15}$, es un puente de fábrica de sillería almohadillada. El material utilizado es una arenisca roja típica de la zona de Marmolejo, Andújar y Montoro, denominada por los vecinos "piedra molinazal6. Algunas dovelas de la boquilla han sido sustituidas por ladrillo. Está formado por cuatro bóvedas de medio punto, la central, la más grande, con 9,35 m de luz, las dos laterales de $3,60 \mathrm{~m}$ y la cuarta de solo 1,40 m, situada en el margen de la derecha. Entre la bóveda central y las laterales presenta dos aliviaderos formados por pequeñas bóvedas de 1,20 m sobre las pilas.. Presenta tajamares en las pilas. Aguas arriba son triangulares, mientras que aguas abajo no destacan casi del plano vertical, resultando práctica-
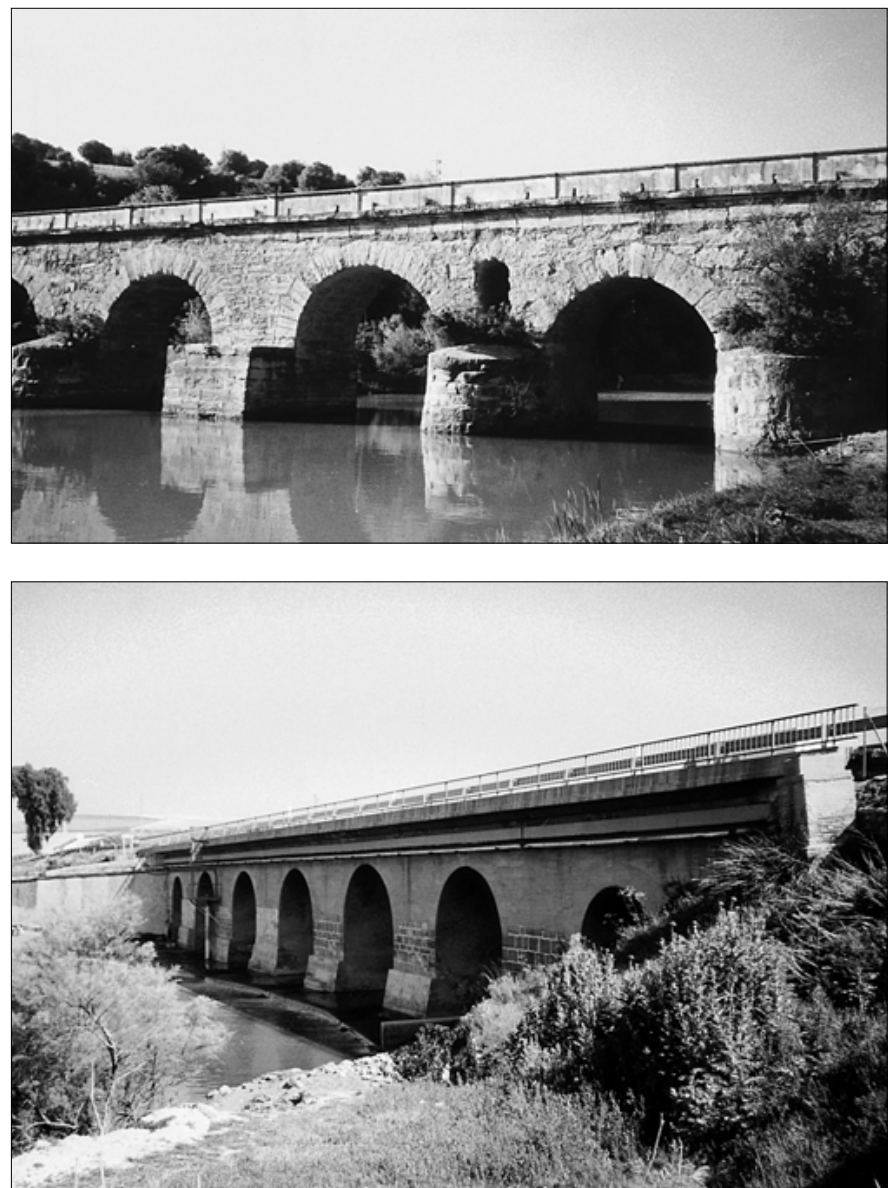

mente planos. Tiene el perfil de la rasante en lomo de asno, tangente a la bóveda central, pero sin eje recto, lo que provoca un ligero quiebro. Se encuentra en mejor estado de conservación el frente de aguas abajo que el de aguas arriba. Se observan reparaciones de distintas épocas en ambos frentes, destacando la obra romana por su mayor fuerza. Hoy está fuera de la Nacional-IV. Se encuentra en una zona de descanso cercana a la carretera, pero sólo es transitable por peatones o vehículos ligeros. Dejó de ser utilizado por la N-IV cuando se construyó en 1936 un puente que cruzaba, formando un ligero ángulo con el arroyo. Era de un tramo abovedado, y desapareció con una fuerte crecida, por lo que se construyó otro para sustituirle, de tramo recto. En la actualidad la N-IV ya no pasa por este lugar, al desdoblarse con motivo de convertirse en autovía.

Muy próximo a la ciudad de Córdoba se encuentra el puente de Rabanales (Fig. 2). Fue construido también durante la etapa republicana, sobre el arroyo del mismo nombre. Formó parte de la vía Hercúlea ${ }^{17}$. En la actualidad apenas es visible, cuando se descubre, se observa que se trata de una obra monumental, más por su carácter que por sus dimensiones, pues cuenta con una longitud de $28,00 \mathrm{~m}$. Está construido en fábrica de sillería muy bien trabajada. Consta de cinco bóvedas de cañón de idéntica luz, 3,75 m. El tablero está sustentado por cuatro pilas del mismo grosor que la luz de las bóvedas. El tímpano presenta pilastras adosadas, que refuerzan el aspecto de solidez. La rasante del tablero es plana. El pretil original ha sido sustituido por otro también de obra.

Algo más alejado de la ciudad en dirección a la población de Villafranca de Córdoba, se localiza, en un bello paraje, el conocido como Puente Mocho, sobre el río Guadalmellato 18 (Fig. 3). También su construcción se corresponde con la etapa republicana. Formaba igualmente parte de la vía Hercúlea, más concretamente del ramal que se desarrolla en el margen derecho del Guadalquivir 19. Es de mayores dimensiones que los dos anteriores, alcanzando una longitud total de 105,00 m. Consta de diez bóvedas de cañón de distinta luz y flecha que oscilan entre los 4,50 a 6,60 m. Está sustentado por gruesas pilas de entre 3,00 y 4,30 m de anchura. En su mayor parte los tajamares no deben ser los originales. Son triangulares aguas arriba y cilíndricos aguas abajo, a excepción de uno prismático. Todos ellos carecen de sombrerete.

En cuanto al tímpano, es macizo, de sillería, aunque más tosco que el de Rabanales. Debió tener arquillos de aligeramiento, pues se observan señales de los mismos entre los primeros arcos. La rasante del tablero es plana. En la actualidad carece de pretiles, debido a la configuración del puente, pero lo más probable es que los tuviera. Es sin duda uno de los puentes romanos más populares, por encontrarse en un lugar muy frecuentado, especialmente en los días de descanso y esparcimiento. 
Siguiendo como punto de referencia con la capital, al otro lado de la misma, en dirección sur por la Nacional IV, a siete kilómetros se localiza el conocido como Puente Viejo 20 (Fig. 4). Como los anteriores es de tiempos republicanos. Formaba parte del camino de Córdoba hacia Sevilla por Écija. Ha sufrido numerosas intervenciones a lo largo de la historia. La más importante en el siglo XVIII, en el que se le adosaron vistosos tajamares. En el siglo $X X$ quedó incluido en el circuito de firmes especiales, durante la década de los treinta. Por último fue recubierto de hormigón en masa, por lo que hoy no se puede contemplar su tímpano original. A pesar de todo conserva su estructura primitiva. Tiene una longitud de $72,00 \mathrm{~m}$. Se compone de siete bóvedas de distinta luz y flecha, éstas oscilan entre los 4,50 a 6,80 m. El tímpano original era de sillería y aspecto macizo. Respecto a la altura de la rasante del tablero es mayor que la de los anteriores. Incluso sin tener en cuenta los recrecimientos producidos por la mejora del camino, alcanza los 9,00 $\mathrm{m}$. No conserva el pretil original de obra.

El Puente Antiguo o del Guadatín (Fig. 5), por situarse sobre dicho arroyo, se encuentra muy próximo a la localidad de Villafranca de Córdoba, junto a la actual autovía en el kilómetro 380. Su origen es posterior a los anteriores, habiendo sido construido en la etapa Imperial. Formó parte de la vía Augus$t^{21}$. Es una estructura de pequeñas dimensiones, pues apenas alcanza los 28,00 m de longitud. Consta de tres bóvedas de cañón iguales, que alcanzan los 5,30 m de ladrillo, con boquilla de sillería. Las pilas son algo más esbeltas que en las obras de la etapa anterior. En este caso no llegan a los dos metros de espesor, concretamente tienen I,90 m. El tímpano es de mampostería, con resaltes cilíndricos de sillería sobre los tajamares. Los estribos son vueltos, con frentes de sillería, con el fin de reforzar el conjunto. En la actualidad el tímpano del lado norte está oculto bajo el terraplén que sustenta a la autovía.

Junto al polígono industrial de Los Chinales, a las afueras de Córdoba, en dirección noreste, se encuentra el puente romano de los Pedroches (Fig. 6), conocido así por el nombre del arroyo que supera. Se trata de un bello puente, construido en la época imperial, que formaba parte, como el anterior, de la vía Augusta a su entrada a la localidad ${ }^{22}$. Es una obra de fábrica variada: mampostería, sillarejo y sillería. Se trata de una estructura de pequeñas dimensiones, apenas alcanza los 35,00 m. Consta de tres bóvedas de cañón, con rosca de sillería de distintas luces. La mayor es la central, de 5,30 m, y la más pequeña es de 1,95 m. Se sustenta por medio de pilas muy gruesas, de 2,35 y 2,65 m. Carece de tajamares y en su lugar utiliza un único y potente contrafuerte. Su tablero no es muy ancho, 4,80 m, presenta la rasante en lomo de asno, alcanzando una altura en su punto más alto de $6,30 \mathrm{~m}$. El detalle más singular del puente es su triple alineación, lo que le confiere un aspecto muy pintoresco. Perdió el pretil original, pero ha sido reemplazado por otro de obra de similares características. Recientemente, en 1998, ha sido restaurado, recuperando no sólo el puente sino
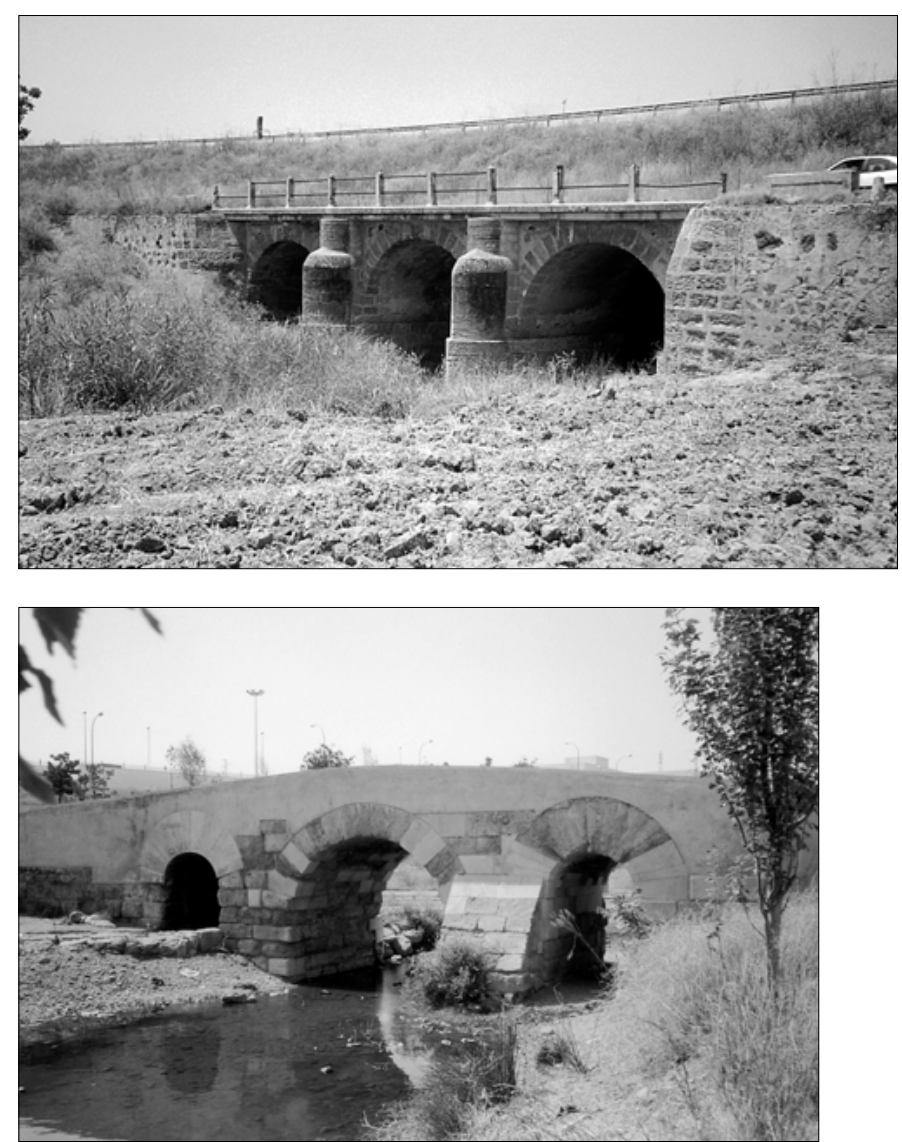

también el entorno anteriormente invadido por escombros. Hoy la zona se ha convertido en un parque público cuyo centro es sin duda el puente.

El gran puente romano de la provincia es el puente de la capital (Fig. 7), sobre el río Guadalquivir. Cruza el gran río con aspecto monumental y una majestuosidad como pocos puentes tienen en la provincia y en España. Su historia está ligada a la de la ciu$\mathrm{dad}^{23}$. Se cree que su origen es de la etapa imperial romana ${ }^{24}$, aunque no todos los estudiosos están de acuerdo. Era el último puente romano fijo que cruzaba el Guadalquivir hasta la desembocadura, pues los romanos no construyeron ninguno aguas abajo. Esta situación se prolongó hasta la construcción del puente de Isabel II o de Triana, en 1852, en Sevilla.

La elección de este lugar por Claudio Marcelo para el emplazamiento de la ciudad había tenido mucho que ver con el indudable valor estratégico del sitio, entre la campiña y la sierra, y su valor para las comunicaciones del momento y futuras, aspecto clave en la conquista y dominio del territorio por Roma. Se tiene noticia de que el río por esta zona era vadeable, pero no en todas las épocas del año. La discontinuidad del posible uso llevó a la utilización de un puente de barcas, descrito por Julio Cesar ${ }^{25}$. Poco después fue sustituido por un puente provisional de madera.

La fecha de su construcción no está determinada por documento alguno ${ }^{26}$. La mayoría de los historiadores que lo han estudiado coincide en que su origen es romano. Se han encontrado numerosos sillares con mar-
Fig. 5: Puente que está sobre el Guadatín, próximo a Villafranca de Córdoba.

Fig. 6: Puente de Los Pedroches, sobre el arroyo del mismo nombre, en las afueras de Córdoba. 


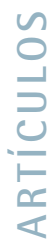

cas de canteros romanos ${ }^{27}$. Por otra parte es muy probable que fuera construido al mismo tiempo que se fundaba y fortificaba la ciudad por el pretor de Hispania, Marco Claudio Marcelo, en el año I52 antes de nuestra era, a causa de la importancia estratégica del lugar en aquella época. De la obra original apenas quedan unos cuantos sillares concentrados en el estribo del arco 16 y en la cimentación. El puente formaba parte de la vía Hercúlea (posteriormente vía Augusta) ${ }^{28}$, que atravesaba la península y comunicaba la ciudad con las vías del otro lado del Guadalquivir.

En conjunto se trata de una obra de sillería abovedada, construida con hormigón hidráulico. En la actualidad consta de dieciséis bóvedas, aunque en origen eran diecisiete, pues se perdió la primera con la construc-
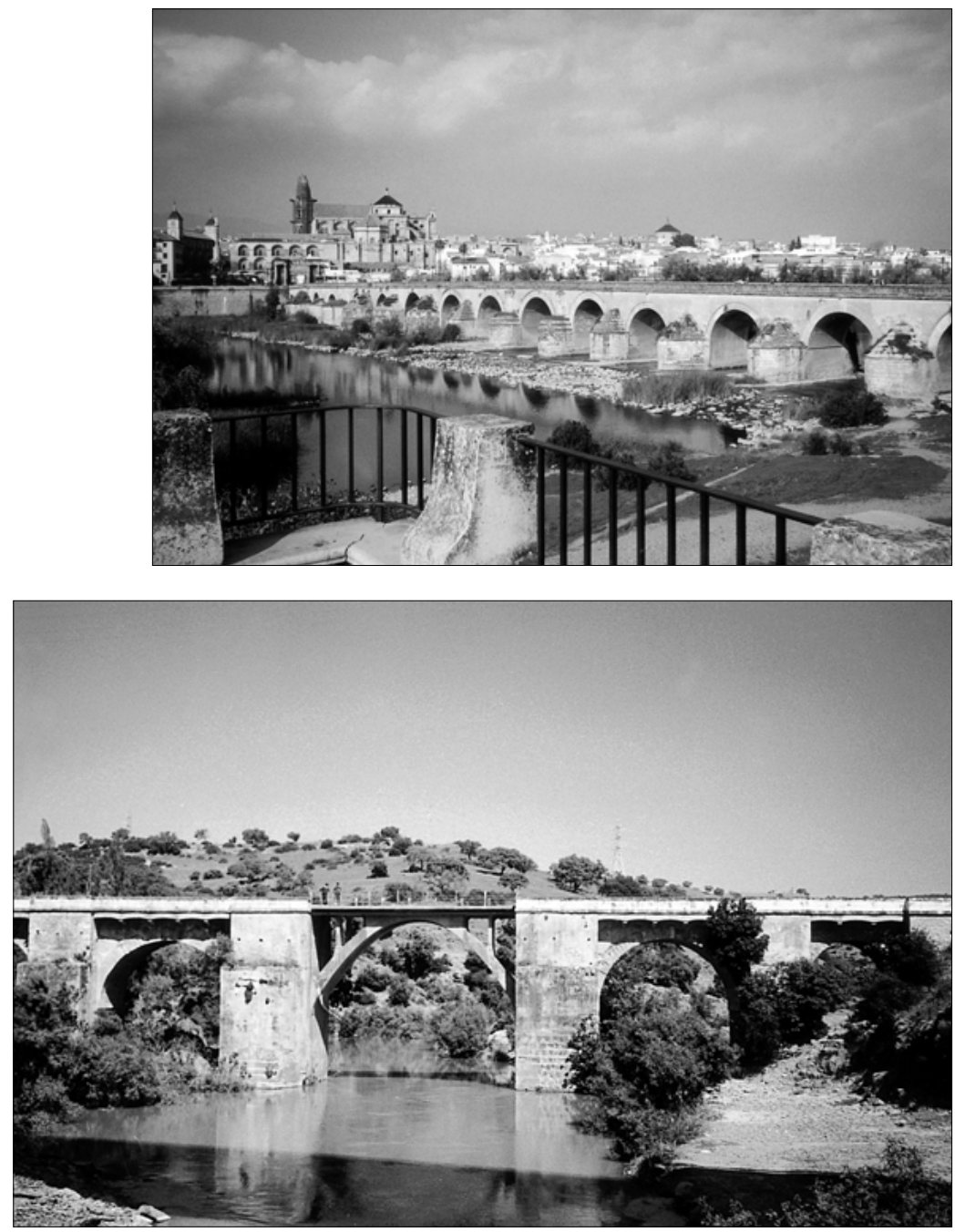

Fig. 7: Puente Antiguo, o de La Calahorra en Córdoba. Vista general.

Fig. 8: Puente de Piedra, sobre el río Guadiato, en Almodóvar. ción de los muros de encauzamiento del río. Tipológicamente pertenece a la categoría de puentes de gran desarrollo longitudinal y no mucha altura, como ya se ha visto en el Puente Mocho sobre el Guadalmellato, pero de mayores dimensiones, como también sucede, por ejemplo, en los puentes romanos de Mérida, sobre el Guadiana, y el de Salamanca, sobre el Tormes 29.

El puente no es recto, pues consta de tres alineaciones, de 104,55, de 107,30 y 62,30 metros. Las luces de los bóvedas son variables, yendo desde los 7,93 $m$ de la más pequeña en el arco decimosexto, junto a La Calahorra, a los 12,82 m del primer arco. Los arcos tienen curvatura variable, resultado de las constantes reparaciones de que ha sido objeto. Mayoritariamente son arcos de medio punto, pero el segundo, tercero, quinto y sexto son apuntados y el primero es rebajado. Los arcos presentan boquillas con arquivoltas que lo diferencian del resto de los puentes romanos. Las bóvedas están sobre pilas muy gruesas y recrecidas de distinta anchura. Los tajamares son triangulares, simétricos en planta aguas arriba y redondeados y apuntados aguas abajo, a excepción de uno cuadrado, el de la pila situada entre los arcos octavo y noveno.

Ha sido objeto de multitud de reparaciones a lo largo de la historia. En tiempos de los musulmanes aparecen las primeras noticias sobre roturas y reparaciones, que se suceden en el $7 \mathrm{II}$, mismo año de su llegada, 720 y 77930 e inclusive en fechas correspondientes al final del Califato, siglo $\times(97 \mid)^{31}$. Las noticias continúan tras la reconquista de la ciudad en 1236 y 1367 sobrepasando a veces el presupuesto razonable del tesoro público, por lo que el propio rey envió al juez pesquisidor, el bachiller Juan Arias de Villar, en I460, para revisar si los trabajos y las cuentas eran admisibles ${ }^{32}$. A partir de I 500 se repiten las noticias acerca del puente. El estado ruinosos de la obra hace que las reparaciones se sucedan, aparentemente sin solución de continuidad. Las noticias continúan en 1505, 1545 y 1579, año éste en el que el estado es tan ruinoso que no se permite el paso de carros y carretas. En el siglo siguiente la situación continúa ${ }^{33}$. Tras un detenido reconocimiento general, en 1694 se llega a la conclusión de que todos los arcos necesitaban nuevas soleras en su zampeado ${ }^{34}$, recalce de algunos y retoques en otros.

El puente llegó al siglo XVIII en estado ruinoso, con seis arcos que amenazaban hundirse y los cimientos bastante mal. En el reinado de Carlos III, en 1772, se Ilama al arquitecto Folch. Éste, en mayo de 1776, presenta un proyecto que recoge las condiciones generales de reparación. Al año siguiente, 1777, comienzan las obras con la dirección del maestro Otero. Ya en el siglo XIX, concretamente en I875, se realizó un presupuesto de reparación de los cimientos que posteriormente se llevó a efecto. En la actualidad continúan las reparaciones, siendo cada vez de menos importancia, debido a su mejor mantenimiento. Así la de 1965 y la última, en 1980 35, con el fin de recalce y consolidación de la cimentación. Su estado actual es bueno. Fue declarado monumento histórico-artístico el 3 de junio de 1931.

\section{Puentes Desaparecidos o Transformados}

Los que se acaban de ver no fueron los únicos puentes que se construyeron en tiempos de los romanos, también nos han llegado otros, pero trans- 
formados en épocas posteriores, como es el caso del conocido como Puente de Piedra, sobre el río Guadiato, en Almodóvar (Fig. 8). Formaba parte del camino de Corduba a Hispalis por el margen derecho del río Guadalquivir. Hoy se encuentra muy próximo a la carretera C-43I, en una variante antigua situada en el $\mathrm{km} 27$. Su aspecto actual se debe a una reconstrucción y transformación llevada a cabo en tiempos de los musulmanes, más concretamente en la etapa califal ${ }^{36}$. La última gran reforma la sufrió al ser destruida su bóveda central durante la guerra civil, siendo reconstruida por medio de una bóveda parabólica de hormigón armado ${ }^{37}$.

Probablemente es de origen romano el conocido como puente de San Pedro sobre el arroyo Malagón (Fig. 9), situado a las afueras de Belalcázar, en el antiguo camino de Corduba a Emerita Augusta 38. La obra debió ser muy transformada durante la Edad Media. A este período se corresponde su aspecto actual, aunque ya en su origen presentaría su perfil alomado. Consta de ocho bóvedas de luz variable de 2,50 $\mathrm{m}$ la menor a 6,00 $\mathrm{m}$.

Algo similar sucedió con el Puente Viejo de Alcolea, sobre el río Guadalbarbo (Fig. 10), situado a las afueras de esta localidad. La primitiva fábrica se debe a tiempos del Imperio romano. Formó parte de la vía Augusta. Con posterioridad ha sufrido numerosas transformaciones. Las que lo configuran tal y como lo vemos en la actualidad, con tres bóvedas de cañón iguales, fueron llevadas a cabo durante la Edad Media.

El puente de los Piconeros (Fig. I I), muy cerca del anterior, se encuentra en la carretera de dicha localidad a las urbanizaciones próximas. Su primera fábrica fue romana. Formó parte de la vía Augusta en el tramo de Castulo a Corduba, también por el margen derecho del río. La obra actual es posterior, debió construirse al final de la Edad Media, aunque no existe documentación que lo atestigüe. Dicha afirmación se basa en el análisis tipológico de la estructura, destacando del mismo la configuración de los arcos y la decoración heráldica esculpida en su tímpano. Consta de tres bóvedas de cañón, la más grande la central de 6,00 m y las laterales de tan solo $3,30 \mathrm{~m}$.

Un caso singular es el puente de Alcolea del Río (Fig. 12), sobre el Guadalquivir. El actual responde a la renovación de infraestructuras realizadas durante el reinado de Carlos III. Fue iniciada su construcción en 1787 y se terminó ya en tiempos de Carlos IV, en 1792. Hay testimonios del antiguo de origen romano, que hoy desaparecido, llegó aunque en ruinas, hasta el siglo XVIII, según indican viajeros como Ponz ${ }^{39}$. La obra sustituida debió ser de grandes dimensiones, teniendo en cuenta el entorno y el puente moderno, con veinte bóvedas, lo que le confiere un gran desarrollo longitudinal40. Además de éstos, es probable que existieran otros, que han desaparecido o han llegado hasta nosotros transformados, sin que se hayan encontrado restos de su origen romano ni documentación que así lo atestigüe.

\section{Conclusión}

Son muchos los temas que se pueden derivar de este artículo. No es necesario señalar el esfuerzo que realizó Roma en la mejora de caminos en toda la extensión de su territorio. De ahí que aún aparezca
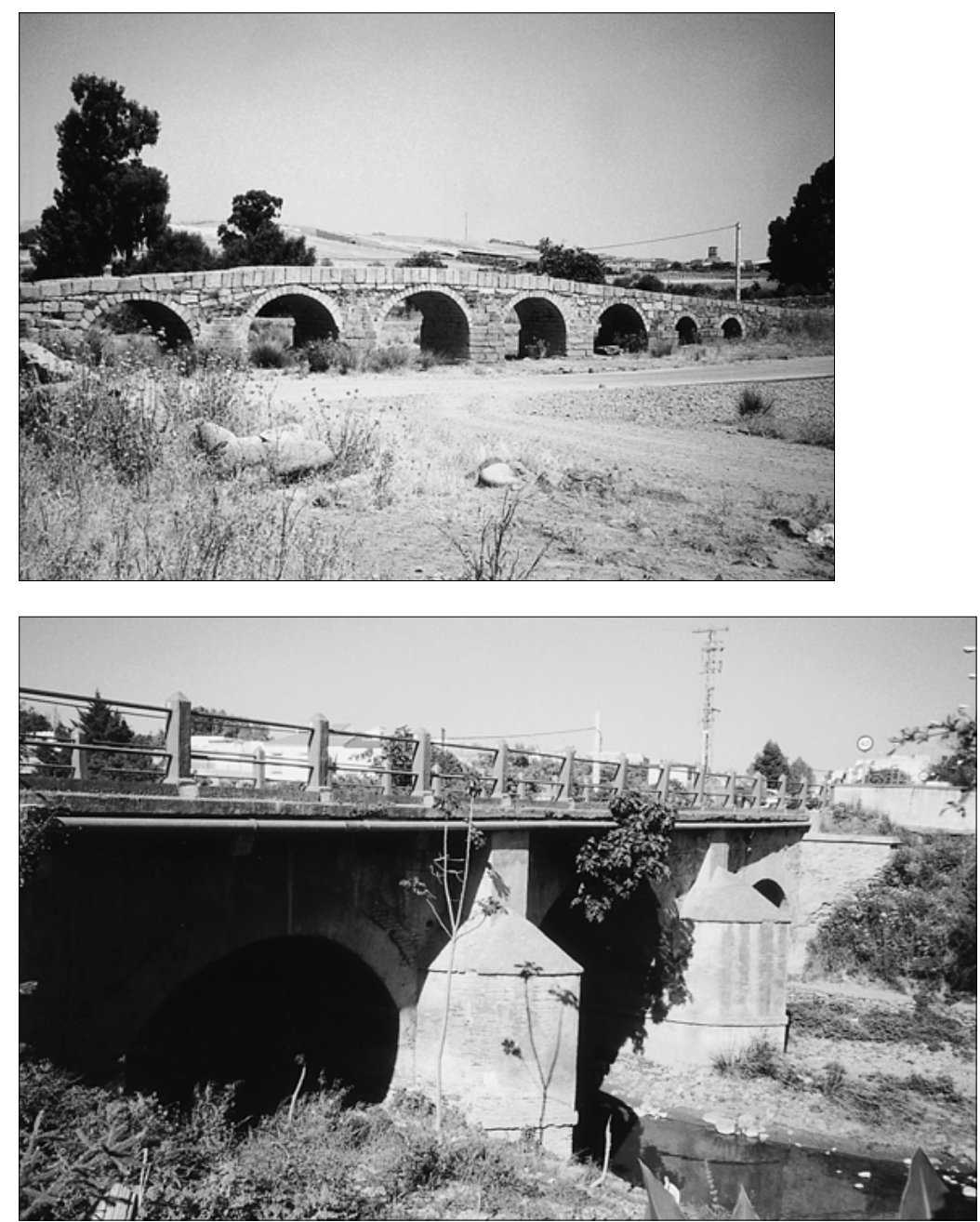

un gran número de restos, obras de calidad que han traspasado la barrera de los tiempos, a pesar de que los caminos y sobre todo los puentes son las construcciones más expuestas a los agentes naturales. Aparte de su importancia funcional, los puentes poseen un valor histórico-artístico que los eleva a la categoría de monumentos y obras de arte.

Tras el estudio de las obras, se puede afirmar que la provincia de Córdoba cuenta con un interesante patrimonio de puentes romanos. Con un panorama tan extenso y de tanta calidad resulta difícil destacar algunas obras. El puente romano de Córdoba o de La Calahorra, sin duda es el más conocido. Su dilatada historia y su posición estratégica han hecho del mismo obra clave del patrimonio provincial. Ha sido por esto el más estudiado, tanto desde el punto de vista técnico como histórico. Junto a esta obra también son reconocidos el de Villa del Río y el de los Pedroches. Como se ha visto, posiblemente sean las piezas que tradicionalmente se han destacado más.
Fig. 9: Puente de San Pedro sobre el arroyo Malagón, en Belalcázar.

Fig. 10: Puente Viejo de Alcolea, sobre el río Guadalbarbo. 

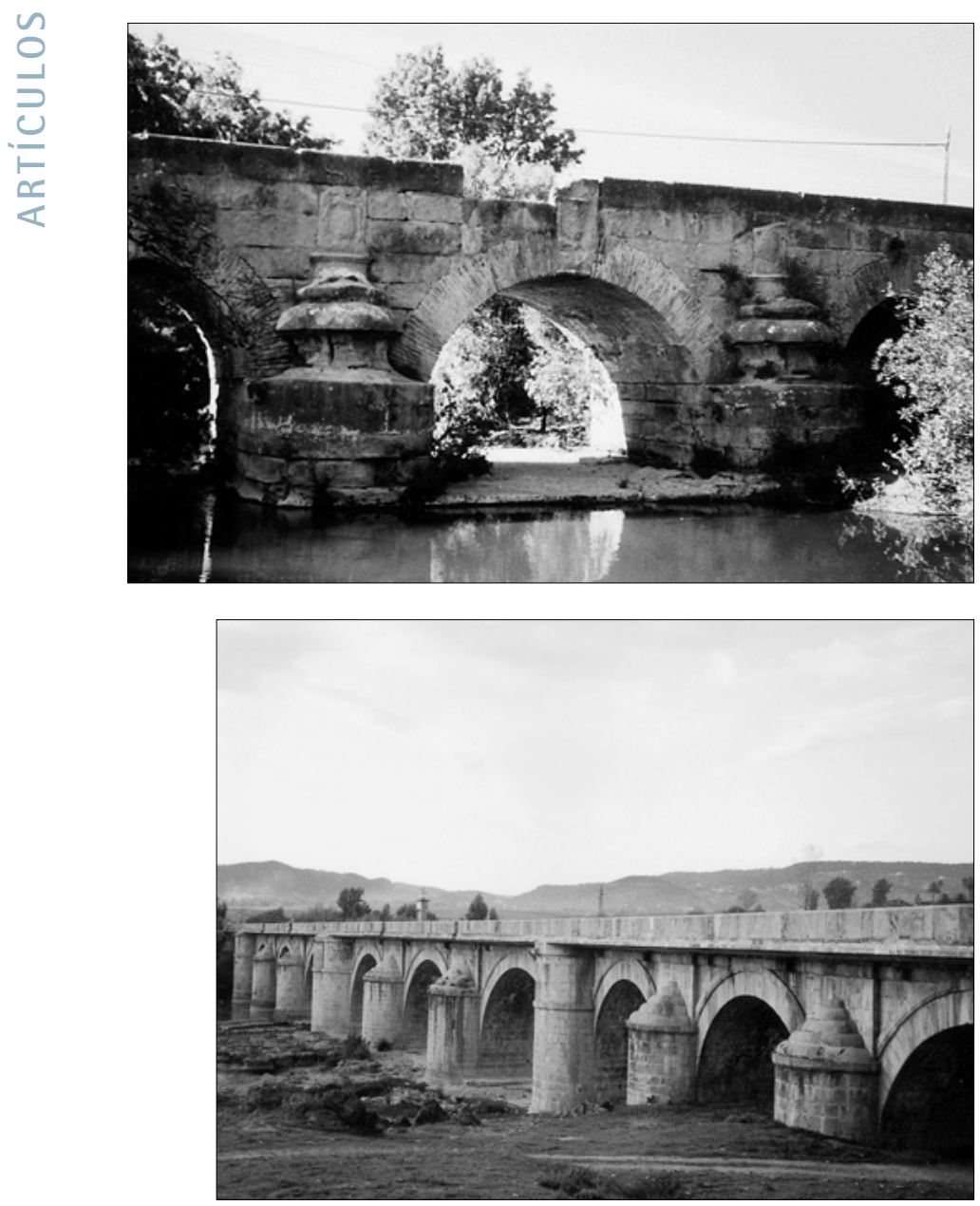

Fig. I I: Puente de los Piconeros, sobre el Guadalbarbo.

Fig. 12: Puente de Alcolea del Río, sobre el Guadalquivir. Detalle.
En lo referente a la conservación de este patrimonio hay mucha irregularidad. Por una parte, se observa una atención correcta hacia los puentes cercanos a núcleos urbanos o a los situados en lugares de cierta importancia, como son los casos de las recientes reparaciones llevadas a cabo por la Junta de Andalucía, Consejería de Obras Públicas, en los puentes de La Calahorra, Villa del Río, y los Pedroches. Pero la otra cara de la moneda, y lamentablemente lo más frecuente, es el abandono y el descuido, como sucede en otros muchos puentes. Se trata de interesantísimas obras, que aún siguen asombrándonos por su magnitud y belleza, pero que han quedado marginados por resultar estrechos a las nuevas calzadas, como ocurre, por ejemplo, con el Puente Mocho o el de San Pedro. Hay casos todavía peores, siendo quizá el más destacado el puente de Rabanales, joya de la ingeniería romana, que hoy está ahogado en una maraña de carreteras y tuberías, muchas de ellas fuera de uso, que lo único que hacen es ocultar una de las obras más bellas del patrimonio de puentes cordobeses. El del arroyo Guadantín que a pesar de estar en uso ha sido parcialmente enterrado por el terraplén de la autovía Madrid-Sevilla, que amenaza con sepultarlo completamente, todavía tiene remedio. No así el caso del Puente Viejo, sobre el Guadajoz, que aún está en servicio, formando parte de dicha autovía, aunque tristemente camuflado bajo capas de hormigón.

Debería existir una mayor conciencia pública de conservación de este patrimonio heredado e irrepetible. Casos como el del puente de la Calahorra o el de los Pedroches, no hace tanto restaurado (abril de 1997) no deberían ser la excepción, sino la norma. La obra arquitectónica se pone en peligro de conservación siempre que deja de usarse. Por ese motivo sería interesante, además de reparar los daños sufridos y conservar las obras, crear zonas de recreo en torno a los mismos. En algunos casos, el público ha tomado las zonas próximas al puente como lugares de recreo de forma espontánea, como sucede en las inmediaciones del Puente Mocho o en el caso del Puente Viejo cercano a Almodóvar. Esto debería servir de ejemplo a la Administración y crear auténticas zonas de esparcimiento en torno a los puentes, con señalizaciones previas de la obra, facilitando el acceso y limpiando el paraje. En los casos de los cercanos a la carretera, como el de Rabanales, resultaría beneficioso crear áreas de descanso en torno al puente, de modo que dejarían de pasar desapercibidos y al menos tendrían un uso peatonal.

En un momento como es el actual, en que se vuelven los ojos a la Naturaleza, si además existe una obra del hombre que se inserta en la misma respetándola y engrandeciéndola a un tiempo, como es el caso de los puentes, sería muy acertado crear rutas turísticas que facilitasen la contemplación y visita de los mismos. Conservemos los puentes. Es un legado histórico en el que nosotros mismos estamos reflejados. Si los perdemos será imposible recuperarlos después.

En definitiva, este breve artículo ha tratado de que se tome conciencia del interesante patrimonio de puentes romanos, tomando como ejemplo la provincia de Córdoba, sin olvidar que es asunto que afecta al resto de la Comunidad de Andalucía y a toda España. Intenta rescatar del olvido y la degradación aquellas obras, hoy abandonadas, que en su día tuvieron una función práctica y todavía pueden ser útiles. Aún hoy, en muchos casos, si nos detenemos a contemplarlas, siguen llamando nuestra atención. 
I. Ver MOLLÁ LÓPEZ, J. "Cuestiones legales en orden a la obra pública. Riesgo, patrimonio y propiedad intelectual". OP, n 40, El patrimonio de las obras públicas, Barcelona, 1997. tomo $1^{\circ}$, pág. 7.

2. ARENAS DE PABLO, J.J., "El puente, pieza esencial del mundo humanizado". Universidad de Santander. Santander, 1982.

3. RODRÍGUEZ NEILA, J.F.: Del amanecer prehistórico al ocaso visigodo. Historia de Córdoba, Monte de Piedad de Córdoba, tomo I. Córdoba, 1988, pág. 212.

4. ARIAS BONET, G.: Repertorio de caminos de Hispania Romana. Cádiz, 1987, pág. 487 y sig.

5. URIOL SALCEDO, J.: Historia del transporte en España. CIC. Turner. Madrid 1980, tomo I, págs. 15 y 17.

6. Idem, págs. 16 y 21.

7. ALZOLA Y MINONDO, P.: Historia de las obras públicas en España. CIC. Madrid, 1979, pág. 63.

8. URIOL SALCEDO, J.: Op cit, pág. 25.

9. Idem, pág. 35 y ALZOLA Y MINONDO, op cit, pág 73.

10. Ibídem.

I I. Uriol Salcedo, J.: Op cit, pág 35.

12. STEINMAN Y WATSON: Puentes y sus constructores. La construcción primitiva de puentes. Madrid, 1979, págs. 33 a 54.

13. Como ingeniero, la obra de Fernández Casado da una visión técnica del "efecto presa" que se produce en gran número de puentes romanos, sobre todo los de época republicana, en los que la relación entre vano y pila es de un 1/2. FERNÁNDEZ CASADO, C.: Historia del puente en España. Puentes romanos. Madrid, 1980, s.p.

14. TARACENA, B.: Las grandes obras públicas. Ars Hispaniae, tomo II. Madrid, 1947, pág. 15.

15. FERNÁNDEZ CASADO, C.: Op cit.

16. CELESTINO ESPINOSA, P., en su relación de artículos publicados en la R.O.P titulados "Reseña de varios puentes construidos en España desde la Antigüedad hasta principios del siglo XIX". Madrid, 1878, pág. 25I. Habla de "asperón rojo" al referirse a la piedra arenisca molinaza.

17. FERNÁNDEZ CASADO, C.: Op cit.

18. CELESTINO ESPINOSA, P.: Op cit, pág. 250.

19. ALZOLA Y MINONDO, P.: Op cit, pág. 50.

20. MADOZ, P.: Diccionario Geográfico-Estadístico-Histórico de España y sus posesiones de Ultramar. Madrid, I847. Tomo 8, pág. 601 . Y BLÁZQUEZ Y DELGADO, A.: Boletín de la Real Academia de la Historia. 1912, tomo 61.

21. RAMÍREZ DE LAS CASAS-DEZA, L.M.: Corografía históricoestadística de la provincia y Obispado de Córdoba. Córdoba, 1986, pág. 212.
22. FERNÁNDEZ CASADO, C.: Op cit. Y W. AA. Puentes de España. FCC. Madrid 1994., págs. 36 y 37.

23. PINILLA MELQUIZO, R.: "El Puente viejo". Córdoba capital. Caja Sur. Tomo II. Córdoba, 1995, pág. 22.

24. FERNÁNDEZ CASADO, C.: Op cit.

25. PAVÓN MALDONADO, B. Tratado de Arquitectura HispanoMusulmana. C.S.I.C. Madrid, 1990, pág 94.

26. PINILLA MELQUIZO, R. Op cit., pág. 22.

27. CELESTINO ESPINOSA, P. Op cit., pág. 250

28. Ibídem.

29. FERNÁNDEZ CASADO, C. Historia del puente en España. Puentes romanos. C.S.I.C. Madrid. 1980.

30. TORRES BALBÁS, L. "Arte Hispano-Musulmán hasta la caída del Califato de Córdoba". Historia de España dirigida por RAMÓN MENÉNDEZ PIDAL. Tomo V. Madrid, 1957, pág. 621. También de esta etapa es la construcción de la primitiva torre de La Calahorra era en origen la torre del puente, con función de puerta de control, y no una entidad independiente. Ver FERNÁNDEZ TROYANO, L. El patrimonio histórico de las obras públicas y su conservación. Los puentes. Informes de la Construcción. Vol. 37. № 375. C.S.I.C. Madrid, 1979, págs. I I y 28.

31. SÁNCHEZ ALBORNOZ, C. La España Musulmana. Madrid, 1973.

32. RAMÍREZ DE ARELLANO, R. Inventario-Catálogo HistóricoArtístico de Córdoba Edición facsímil. Córdoba, 1982.

33. URIOL SALCEDO, J.J. Op. Cit, pág. 154.

34. Zampeado: Técnica utilizada para calzar los pilares del puente cuando no existe roca madre superficial. El procedimiento es la creación de un emparrillado reticular por medio de vigas de madera tratada contra la humedad. En los vértices de cada retícula se clavan los pilotes. El resto de la retícula se adoquina. Esta técnica era comúnmente utilizada para la construcción de puentes antes del siglo $X X$.

35. Informe de la Jefatura Provincial de Carreteras. Madrid, 9 junio 1978.

36. MADOZ, P.: Op cit., Tomo 6, pág. 586 y tomo 9, pág. 39.

37. Jefatura de Obras Públicas de Córdoba: "Puentes destruidos durante la guerra civil”. R.O.P. 1936-39, pág. 133.

38. RAMÍREZ DE LAS CASAS-DEZA, L.M.: Corografia HistóricoEstadística de la provincia y Obispado de Córdoba. Córdoba, 1986, pág. 50.

39. "Yo he pasado en ocasiones este río por el antiguo puente que me pareció en gran parte de fábrica romana, pero estaba ya muy deteriorado, y era demasiado angosto. Si no me engaño le conté veinte arcos". PONZ, A.: Viaje de España. Facsímil. Madrid, 1972. (1787). tomo XVI, carta sexta, pág. 275.

40. MADOZ, P.: op. cit., tomo I, pág. 453. 